\title{
Students’ Metaphors for Defining Their Learning Experience with Audio-Visible versus Invisible Authors. Results from a Case Study in a Social Science Discipline
}

\author{
Terry Inglese, Francesca Rigotti \\ New MinE, New Media in Education Lab of the Università della Svizzera Italiana, \\ University of Lugano, Lugano, Switzerland. \\ Email: inglese.terry@gmail.com, francesca.rigotti@lu.unisi.ch \\ Received January 19 ${ }^{\text {th }}, 2011$; revised March 10 ${ }^{\text {th }}$, 2011; accepted March $18^{\text {th }}, 2011$.
}

\begin{abstract}
This article summarizes an instructional experience designed and conducted at the University of LuganoCommunication Sciences-(Switzerland) within a Political Theory's freshmen course, which involved disciplines like: philosophy, political science and epistemology. We offered students two types of authors to be learned: one through a multimedia video interview in combination with written texts of these authors, defined as the audio-visible authors, and one type of author offered only through a text-based format (the invisible author). We gathered quantitative data (students' performance on their written exam compositions, their grades; the number of written words they wrote; and the number of times students mentioned the two types of authors in their written compositions). We also collected qualitative data (through semi-structured interviews and thinking aloud protocols), analyzing the metaphors students used to define the reading and learning experience with the audio-visible and the invisible authors. Results show that students perform better when the author to be studied is offered with more media instructional supports, they tend to establish a social relationship with the author, and the quality of their critical thinking and the level of interest in a new subject both increase. The article is divided in three parts: we will first give some definitions of what a metaphor is; second, we will describe our case study and the results of the data analysis; third, we will discuss the results.
\end{abstract}

Keywords: Multimedia Learning, Metaphors and Learning, Audio-Visible Author, Invisible Author, New Media and Learning, Digital Learning

\section{Introduction}

According to several contemporary philosophers (Collenberg-Plotnikov, 2006), also philosophy as a discipline is trying to understand the impact of the new media on its discipline, and looking for scientific research methods to comprehend the so defined "iconic turn", or "visualistic turn". In this article we focus on Social Sciences' disciplines such as philosophy, political theory, communication theory and how multimedia might promote in freshmen, with low prior knowledge in these fields, an engaged interest in critical thinking.

We explore these areas taking into account the learning effects on students' performance combining audio-visible interviews with important scholars which are usually only read through written texts (the Austrian philosopher Paul Feyerabend and the French anthropologist Claude Lévi-Strauss) and authors presented only through a text, such as the Italian scholar Andrea Semprini. The video interviews, produced in the late 70ies and 80ies, were extracted from the public TV archive of the RTSI-Lugano (Switzerland). The iconic turn is here represented by the technical, as well as the instructional opportunity to access and use old but very unique and vivid materials stored in archives, such as a multimedia interview with a Social Science scholar usually read and learnt only through a written text. The end goal is to study the learning effects on students which have never read, heard or seen these authors. The students' population was divided in two groups: an Italian native speaker group and a non native Italian speaker one.

Through our analysis about students' metaphors on reading and studying works of these audio-visible authors, compared to only text-based authors, we demonstrate that there are three levels of languages: the language of the discipline (philosophy and political science), the instructional design language about how to teach these disciplines, and the language that students used to write and read these two types of authors. One of the key we choose to interpret the cause-effect of our instructional choice is the analysis of the metaphors students expressed to define their learning experience.

\section{A Definition of Metaphor}

Metaphor is a word or phrase applied to an object or a concept that it does not literally denote it, and is suggesting a comparison with another object or concept. A dictionary definition is not enough to cover all the meanings related to the explanation of the metaphor, which has several interpretations according to the discipline which understand it. Rigotti $(1995,1996)$ undertook several metaphorical analyses in different areas of knowledge and ages, such as the influence of rhetoric in ethics, religion, psychology, agriculture and political contexts. But "metaphorology is not an exact science; metaphors and their components do not have precise outlines and established perimeters” (Rigotti, 1996: p. 2).

Metaphors are primarily linguistic phenomena. Their main 
function is to provide an alternative linguistic mechanism for expressing ideas, as well as having a communicative function. According to Black (1993), a metaphorical statement can sometimes generate new knowledge by changing relationships between the things designated. Ortony (1975) considers the role of metaphor as a tool for overcoming active memory limitations in the use of spoken language. There are three theses for exploring how metaphor may facilitate learning: the compactness thesis, where metaphors work by transferring chucks of experience from well-known to less well-known contexts; the vividness thesis, which maintains that metaphors impress a more memorable learning due to the imagery or concreteness or vividness of the experience conjured up by the metaphorical vehicle; and the inexpressibility thesis, in which it is noted that certain aspects of the natural experience are never encoded in language and metaphors carry with them this extra meanings never encoded in language. These characteristics have its origins in the oral language and serves as a tool for cognitive economy by helping to transfer information in large chunks.

Sticht (1996) distinguishes the two types of metaphors: the metaphor as a tool for communication, as an exchange of information among speakers and listeners (for example in our case: how students communicate about the learning experience with the multimedia authors compared to the invisible author); and the metaphor as a tool for thought, concerned with the discovery of relationships between disparate domains and the exploration of the extent to which they can be related (for example in our case: how students describe the cognitive impact of these authors on reading and learning).

After revising studies on metaphor in different Social Sciences (Lakoff \& Johnson, 1980; Glucksberg \& Boaz Keysar, 1996), such as anthropology, sociology, linguistics, cognitive psy- chology and learning (Mayer, 1993), philosophy of science, and epistemology, Ortony (1993) summarizes two opposing conceptions: 1) metaphor as an essential characteristic of the creativity of language (the constructivism); and 2) metaphor as a deviant usage about the relationship between language and the world (the non-constructivism). More specifically, "The con- structivist approach seems to entail an important role for meta- phor in both language and thought, but it also tends to under- mine the distinction between the metaphorical and the literal. Because for the constructivist, meaning has to be constructed rather than directly perceived, the meaning of non-literal uses of language does not constitute a special problem. The use of language is an essentially creative activity, as it its comprehend- sion. ... By contrast, the non constructivist position treats metaphors as rather unimportant, deviant, and parasitic on nor- mal usage. If metaphors need explaining at all, their explana- tion will be in terms of violations of linguistic rules. Metaphors characterize rhetoric, not scientific discourse. They are vague, inessential frills, appropriate for the purposes of politicians and poets, but not for those of scientists because the goal of science is to furnish an accurate, literal description of physical reality.” (p. 2)

Our analysis is a constructivist one, because we can identify, behind the students' collection of metaphors, their feelings and perceptions of how they related with the two types of authors. For this reason, we will first provide some statistical analysis' results of our case studies (the quantitative data), and then the qualitative analysis, and specifically the metaphors students used to describe their reading and learning experience with the two types of authors. We provide a data triangulation, where the quantitative and the qualitative data sets complement each other.

\section{Description of the Case Study}

We designed the following instructional scenario: reading and studying an author through written texts characterized by a formal, academic, "difficult" type of writing and with a very low social presence percentage (the invisible author Andrea Semprini) compared with reading and studying authors proposed through an audio-visual interview, using a dialogic I-you format, through texts that are complex, but where the level of social presence is high (the use of TV interviews with the French anthropologists Claude Lévi-Strauss and the Austrian philosopher Paul Feyerabend). For the level of social presence we intend how many times the authors speak in first person and address their discourse to an audience, establishing an I-you relationship with the audience (Paxton 1997, 1999, 2002; Brand (1990), Inglese et al. (2007)).

We looked for cognitive gains in the quantitative data, taking into account: 1) the grades on the written composition exam questions' for the native Italian speaker students, as well as the non-native ones; 2) how many words students wrote in their written compositions, and 3) how many times students mentioned the two types of authors (the audio-visible and the invisible authors) in their texts.

From the qualitative data collection, we measured the levels of comprehensibility, interest and emotional cohesion students reported to have established with the two types of authors, as well as the types of metaphors they used in the thinking aloud protocols and interviews.

Two were the independent variables: first, the second language perspective of the non-native Italian speaker students; second, the impact of the audio-visibility and the invisibility of the author to study on students' performance for both linguistic groups.

\section{The Population}

The class was composed of 108 university freshmen (84 females, 24 males) and divided into two linguistic groups: 60 native Italian speakers and 48 non-native ones, as a real multicultural mix with students coming from 15 different countries and speaking a total of 13 different languages. The average age was from 20 to 25 years old. The class was made up of approximately $70 \%$ female students.

\section{The Case Study}

The case study took place during the academic year 20042005. The course dealt with the abstract concepts such as: democracy, mono-culturalism and multiculturalism, liberalism, universalism, and cultural relativism, exporting democracy into non-democratic countries, collective and individual human rights, and the meaning of citizenship. The professor selected excerpts from rather long TV interviews with the two audio-visible authors. We uploaded them on the Moodle learning platform, which we used as a storage instrument for all the instructional materials. 


\section{The Audio-Visible and Invisible Authors}

\section{Claude Lévi-Strauss (1908-2009)— the Audio-Visible Author}

In a one hour interview, conducted in 1982 by the Swiss Television of Lugano, Lévi-Strauss answered several questions posed by a journalist. The professor chose two video-excerpts from a one hour interview. In the first video, Lévi-Strauss explains the concept of racism. From his studies, racists' supporters define intellectual and moral attitudes as functions of genetic heritage. If a person doesn't possess a similar genetic heritage, the so called "other" is rejected and stigmatized as an inferior. The anthropologist labels this racist conviction as "monstrous" and "absurd" from both the ethical and the scientific point of views. But he goes on in mentioning that generally people, including the ones who are not racist, do not love other people who are not similar to them. This is also supported by the fact that anthropological studies of non-western populations do not interest western societies. This is reflected in westerners' verbal expressions for foreigners, such as "savages", "barbarians”, “enemies”, “louses' eggs”. Lévi-Strauss concludes that most people cannot believe their own values while at the same time accepting the values of different cultures. The essence of his statement is an invitation to understand the concept of racism from an anthropological point of view, which is often hidden in our language expressions.

In the second video, he outlines the presumed differences of superior and inferior societies between the so called civilized and savage populations. Ultimately, he argues that there are no absolute terms in referring to the difference of societies. Even if one argues that Western society has had superior scientific reasoning and technological progresses, one must admit that the price for this progress has been the estrangement from nature. On the other hand, societies with little technological progress and scientific expertise, he argues, usually have a deeper connection with nature. Lévi-Strauss concludes that all value judgments about societies are relative. Assuming otherwise means that "at the end we pay a price for these superiorities!"

\section{Paul Feyerabend (1924-1994) — the Audio-Visible Author}

The roles of experts in a democratic society were the focus of the TV interview with the Austrian philosopher of science Paul Feyerabend. He is known for his provocative critique of science and its methods, and for attacking the tendencies of scientists to be too dogmatic, objective and often too narrow focus.

In the selected excerpt from the interview, the philosopher defines the responsibilities of scientists and experts in a democratic society. From his perspective, experts and scientists are necessary, even if they are not perfect. But they need to be controlled, because very often they make mistakes and hence we need an institution that monitors them. Feyerabend gives the following example: if someone decides to build a nuclear reactor in a certain area this decision concerns everybody in the surrounding area, because if the nuclear reactor fails a general catastrophe could affect millions. Therefore it is necessary before constructing the reactor to consult various experts. But the ultimate decision is one that should be decided upon by the local population in a democratic manner. Feyerabend adds that in California, citizen's committees fought an attempt by government to build a nuclear reactor in their area, reminding the experts that California is subject to earthquakes and that a geo- logical examination is necessary before building a reactor. Citizens, not experts, demanded a geological examination of the area, but the experts focused only on their expertise while ignoring the danger under their feet by refusing to undertake any geological examinations. In this case, in a democratic society, citizens act as a body to monitor experts. He then gives other concrete examples in support of this notion of a check against the single-mindedness of experts by a democratic citizen body and highlights the power that such a body can have in a democracy.

\section{Andrea Semprini-the Invisible Author}

The Italian multiculturalism scholar Andrea Semprini was the invisible author. He was 'invisible' in two ways: first, because he was not seen and heard and second, because he is writing his texts in a mostly detached, formal and academic way. He was introduced by the professor through several presentations concerning his text, his models and concepts about the phenomenon of multiculturalism compared to the mono-culturalism. His text was a required reading for the final exam and contained two key concepts: 1) the differences between monoculturalism and multiculturalism; and 2) four abstract models Semprini developed for explaining the multiculturalism concept.

\section{Additional Course Materials}

Additional course materials were: the course syllabus; five textual transcriptions of the audio-visible authors' videos; the weekly slides of the corresponding lectures; pictures and slides of all the authors presented during the course, with a brief description of his theoretical significance and how it relates to the course; the teacher's lectures transcribed (the dispense); an article written by the professor and the text of Semprini about multiculturalism. (Semprini, 2002).

\section{Procedure}

Each video of the two audio-visible authors was shown twice in class and was preceded by the instructor's introduction. The first screening provided students with an introduction to the audio-visible author. We then gave the transcript of the video just seen to the students, followed by a second screening of the same video. The students could then follow the second screening, either reading the text and/or listening to and watching the audio-visible authors. A discussion between the teacher and the students followed after the second screening. The text of the invisible author was read by the students outside the classroom activities as the book to study.

\section{Measuring the Social Presence of the Audio-Visible and the Invisible Author's Texts}

We measured the social presence of the authors' texts by counting how many times the three authors were using the first person singular and plural, the second person singular and plural, the presence of rhetorical questions, examples and the total amount of words. We adopted the counting methodology from Paxton (1997, 1999, 2002), with the hypothesis that this kind of measure might have an impact on how students perceived these texts, as well as the relationship with these authors.

As we see from Table 1, the Lévi-Strauss's text was characterized by a $1.90 \%$ of social presence, the Feyerabend's one by 
Table 1.

Measurement of the first person singular and plural, the second person singular and plural, the presence of rhetorical questions, extracted from the TV interview transcriptions.

\begin{tabular}{cccc}
\hline & $\begin{array}{c}\text { Lévi-Strauss } \\
\text { (700 words) }\end{array}$ & $\begin{array}{c}\text { Feyerabend } \\
\text { (558 words) }\end{array}$ & $\begin{array}{c}\text { Semprini } \\
\text { (2141 words) }\end{array}$ \\
\hline I & $1.10 \%$ & $0 \%$ & $0 \%$ \\
you & $1.30 \%$ & $0.20 \%$ & $0 \%$ \\
we & $2.10 \%$ & $0.50 \%$ & $0.20 \%$ \\
questions & $0 \%$ & $0.40 \%$ & $0 \%$ \\
examples & $0 \%$ & $0.70 \%$ & $0 \%$ \\
Total & $\mathbf{4 . 5 0 \%}$ & $\mathbf{1 . 8 0 \%}$ & $\mathbf{0 . 2 0 \%}$ \\
\hline
\end{tabular}

$3.90 \%$ and the Semprini's text by $0.20 \%$ of social presence. We are aware that the audio-visible authors were perceived as more 'present' than the invisible one, because of the TV interviews.

\section{Data Collection}

\section{The Quantitative Data}

\section{The Written Compositions Results}

The final exam consisted of six questions: two were dedicated to the audio-visible authors and one to the invisible author. The other questions were devoted to other materials studied in class, which we did not analyze. Non-native Italian speaker students were given the option of answering in: French, English, Spanish or German. From a class of 108 students, 86 (46 native Italian speakers and 40 non-native Italian students) took the exam at the end of the course. The professor gave scores from 0 (very low) to 10 (very high). Each question was given a separate grade by her, so we were able to compare the performances for each type of author and questions. We analyzed: 1) the grades for the audio-visible and the invisible authors' questions; 2) the number of written words students wrote and 3) the number of times they mentioned the two types of authors in their written compositions.

\section{Descriptive Statistics}

The average grade for the 46 Italian speaker students for the visible authors was $7.98(\mathrm{SD}=1.71)$ and the average grade for the invisible author was 7.17 ( $\mathrm{SD}=3.05$ ). The average grade for the 40 non Italian speaker students for the visible authors was $7.40(\mathrm{SD}=1.74)$ and the average grade for the invisible author was $5.80(\mathrm{SD}=3.57)$.

How many words, on average, did the native and the nonnative Italian students write for the questions on the two audio-visible authors and on the invisible one?

Scardamalia and Bereiter $(1987,1991)$ found that the number of words in students' writings correlates substantially with indicators of the quality of their writings. Here, the assumption underlying the word counting is that if students feel the author more socially present, they might establish a personal relationship with him/her, and therefore they might write more words. In order to prevent students from being rewarded for mere verbosity, they were told by the teacher that they would be graded for the content and not for the length of the exam's answers.
The average number of written words for the 46 Italian speaker students for the visible authors was $161(\mathrm{SD}=61.53)$ and the average number of written words for the invisible author was 160 (SD = 86.13). The average number of written words for the 40 non Italian speaker students for the visible authors was $156(\mathrm{SD}=66.20)$ and the average number of written words for the invisible author was 111 (SD = 90.18).

How many times, on average, did the native and non-native Italian students mentioned (through the name of the author and/or his personal pronoun, or personal reference, for example "the philosopher") the two types of authors?

Again the assumption is that if students feel the author more socially present, they might mention him/her more times in their written compositions. The average number of quotes for the 46 Italian speaker students for the visible authors was 2.9 $(\mathrm{SD}=1.31)$ and the average number of quotes words for the invisible author was .60 (SD = .64). The average number of quotes words for the 40 non Italian speaker students for the visible authors was $2.87(\mathrm{SD}=1.81)$ and the average number of quotes words for the invisible author was .32 $(\mathrm{SD}=.52)$.

\section{ANOVA Tests}

We collapsed the data of the two audio-visible authors Feyerabend and Lèvy-Strauss in one visible variable. We conducted a multivariate ANOVA to test the effects of language (Italian vs. non Italian native speaker students) and author visibility on the three dependent variables: 1) grade; 2) the number of words; and 3) the number of quotes referred to the visible vs. non visible authors written by the students in their compositions. We found a main effect of visibility on grade, $F(1,257)=14.84, p$ $<.001$. We also found a main effect of visibility on numbers of word $F(1,257)=5.71, p<.05$. There was a main effect of visibility on quotes $\mathrm{F}(1,257)=191.87, p<.001$. We found a main effect of language on grade, $\mathrm{F}(1,257)=9.68, p<.01$. We also found a main effect of language on numbers of word $F$ $(1,257)=7.83, p<.01$. There was no main effect of language on quotes. There was an interaction between visibility and language on number of words $\mathrm{F}(1,257)=5.24, p<.05$.

\section{The Qualitative Data}

The research methodology we used to gather the qualitative data was the thinking and feeling aloud protocols (Pressley, Afflerbach, 1995; Ericsson, Simon, 1984, 1993), a methodology that keeps tracking the cognitive processes while people do a certain activity, which in our case was reading texts of the audio-visible versus invisible authors of the case study. There are also three other advantages in using this methodology: 1) it provides data on cognitive processes and reader responses that otherwise could be only investigated indirectly; 2) it provides access to reasoning processes underlying sophisticated cognition, response, and decision making; 3) it allows for the analyses of affective processes of reading in addition to or in relation to cognitive processes.

Brandt (1990) appreciates this methodology as a "process centered" approach as insightful and as a new area of inquiry in reading pedagogy, because it offers a new glimpse into literacy in action, for understanding literacy and literacy development, showing how the meaning of textual language is tied to what is going on in the reader's here-and-now working context. Oral protocols are rich records of the social contexts of writing and reading, providing social context is not construed as an external, 
reified force but as something that writer or reader is accomplishing as part of the act of composing or comprehending.

\section{Participants}

Twenty-eight students (over a class of 108 students) were randomly assigned to the task. They represented one fourth of the class.

\section{Materials}

The texts used were: one text of Lévi-Strauss (2002) composed by 162 words. The second text was from Feyerabend (1981) and composed by 258 words. The last text was written by the invisible author Semprini (2000), which consisted of 197 words. The criteria of selection of these texts were their relevance to the course contents. These texts needed to be approximately the same length (number of words) and be the same in the difficulty level of reading and understanding.

\section{Measuring the Social Presence of the Texts Used for the Thinking and Feeling Aloud Protocols}

In Table 2 we summarized the measurement of the three texts' social presence "effect” by counting how many times the authors used the first person singular and plural, the second person singular and plural, the presence of rhetorical questions, examples and the total amount of words. As mentioned in then previous section, the counting methodology was adopted from Paxton (1997, 1999, 2002).

The Lévi-Strauss text was characterized by a $1.90 \%$ social presence, the Feyerabend one by $3.90 \%$ and the Semprini's text by $1 \%$. Of course, we are aware of the fact that the two audio-visible authors had the advantage of being more present, more studied, more quoted, and more presented through a dialogic and audio-visual approach.

\section{Procedure}

Participants were invited to: 1 ) reading aloud texts passages of the three authors; 2) paraphrasing and taking position towards what the authors are arguing; 3 ) describing the reading experience of the authors; 4) describing the level of: a) comprehensibility of the texts; b) difficulty of the texts; c) interest that the these texts promote; d) emotional cohesion towards the authors read through the following questions: Which is the

Table 2.

Measurement of the first person singular and plural, the second person singular and plural, the presence of rhetorical questions from the texts of the authors.

\begin{tabular}{cccc}
\hline & $\begin{array}{c}\text { Lévi-Strauss } \\
\text { (700 words) }\end{array}$ & $\begin{array}{c}\text { Feyerabend } \\
\text { (558 words) }\end{array}$ & $\begin{array}{c}\text { Semprini } \\
\text { (2141 words) }\end{array}$ \\
\hline I & $0 \%$ & $0.40 \%$ & $0 \%$ \\
you & $0 \%$ & $0 \%$ & $0 \%$ \\
questions & $1.90 \%$ & $1.90 \%$ & $10 \%$ \\
examples & $0 \%$ & $0.80 \%$ & $0 \%$ \\
Total & $0 \%$ & $0.80 \%$ & $0 \%$ \\
\hline
\end{tabular}

most comprehensible, interesting and the most emotionally near author and why?

\section{Data Collection}

All interviews were audio taped and transcribed. Transcripts were first reviewed informally and after additional reviews, metaphors were identified. The goal was not to come up with a detailed map of cognitive processes, but to get an overall view of students' thoughts while reading the three texts. The transcribed protocols were analyzed to determine whether students considered the audio-visible versus invisible authors as a major influence on their understanding through their metaphors.

\section{Results}

The following graph shows which the most comprehensible, interesting and the most emotionally closer author for the students.

A consistent pattern in the data, graphically summarized in Figure 1, is that the audio-visibility of an author counts for the comprehensibility, the interest, and for the emotional cohesion factor: Feyerabend was the most appreciated by the students, followed by Lévi-Strauss.

\section{The Metaphors' Analysis}

We analyzed the metaphors used by the students, which unwarily expressed their considerations regarding the two types of authors studied through different modalities. We identified some metaphors and their metaphorical fields (Peil, 1993) and compared them using couples of opposite metaphors (Lloyd, 1966).

1) heavy, dry, sterile (pesante, secco, sterile-translation from Italian)

This first group of metaphors: heavy, dry, sterile, is associated to the invisible author (Semprini) and is introducing the idea of the instructional material being terrestrial, meaning the characteristics of an unpleasant touch to a mass of heavy and dry piece of soil. The students described the Semprini's text as they would have in their hands a cloud of arid soil or a clay brick, which both are heavy, dry, sterile.

2) light, flowing, fluid (leggero, scorrevole, fluido- translation from Italian)

This second group of metaphors interprets the instructional

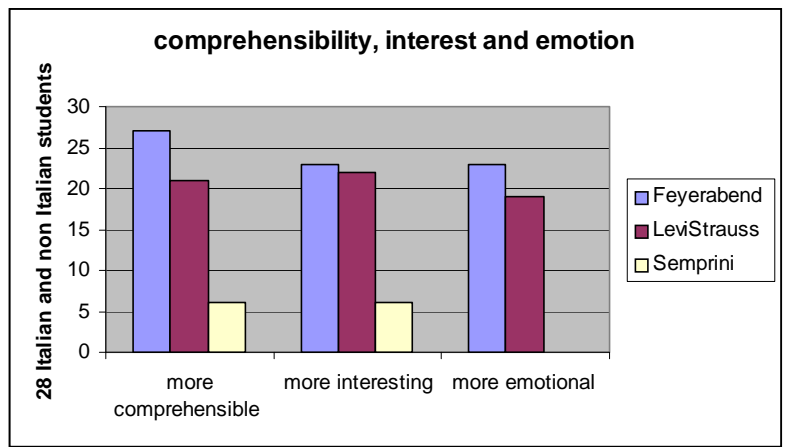

Figure 1.

Qualitative data: measurement of comprehensibility, interest and emotion rating of both groups of students toward the three authors. 
material through an aquatic filter. Lightness, flow, fluidity are in fact characteristics of water and generally of liquids. The students described the audio-visible authors' texts as something being fresh and pleasant in which they can immerge the hands (of the mind) (Heidegger, 1985), as they would grasp the concepts (die Begriffe) with both hands (as the German word begreifen implies) in a tactile manner (Hegel, 1970). One student commented that the thought of Feyerabend is palpable, emphasizing its pleasant consistency, because it is fluid and flowing. These perceptions are contrasted with the unpleasant feeling of heaviness and aridity of the written pages of the invisible author.

3) hard, hostile (duro, ostico - translation from Italian)

This third group lists the metaphorical images attributed to Semprini's text, and are partly similar to those of the first group (heavy, dry, sterile) with an additional and different element: the metaphors of hard and hostile give an idea of the instructtional material being almost impossible to grasp, because rigid and difficult to immerse the hands of the mind. Also from the perspective of affection and feeling, a person who is defined hard it means that she/he is not easy to approach.

4) fragile, sensitive, open (fragile, sensibile, aperto — translation from Italian)

We arranged these three metaphors in one unique metaphorical field, because they evoke an idea of delicacy (fragile) and of easiness of entering into an "open" thought structure. All these metaphors are attributed to the visible authors.

5) twisted, muddled, tied (contorto, ingarbugliato, annodato -translation from Italian)

We enter here in a metaphorical field which is very specific and circumscribed in the imaginary, but difficult to recognize from whom is using it: that is to say, the metaphorical background of the thought's thread (Rigotti, 2002). This metaphorical background is inspired by the idea that the thought (the thinking process) corresponds to a rough and irregular material, composed of wool's, linen's or cotton's tufts, which are ruffled and impossible to understand. If these "tufts" are worked with the fingers, wringed and spun, slowly the thought's/the thinking thread is becoming to be arranged in a linear and continuous thread, intertwined with other threads, of fibers or of thoughts, until it is becoming a texture, which allows to express ideas and concepts in a orderly and sequential manner. Using the following terminology (twisted, muddled, tied) to define Semprini's text, students are expressing their difficulty in understand it.

6) linear, not twisted, that goes in one direction (lineare, non contorto, unidirezionale)

If a thought is linear, it means that it flows on a line (from Latin, linea, which means little cord of linen) and that follows a meaning and a direction ("that goes in one direction"), and therefore, it is not twisted, it does not wrap on itself, it does not come back to carry out new or superfluous circle. The linear thought will be possible to cover with the finger of the mind, in a digital manner (from Latin, digitum, which means finger) without being forced to do sudden and irrupted stops, or jumps and returns. It is a thought which has a continuous dimension that students can control and understand, as the thoughts of Feyerabend and Lévi-Strauss.

7) complex, complicated (complesso, complicato)

This group of metaphors offers another example which refers to the metaphorical textile. Both terms derive from the Latin word plica (which means pleat) and they express the idea that a type of reasoning can contain many pleats (Rigotti, 2007; Deleuze, 1988) (from Latin cum, which means with and together). The metaphors of this group are similar of those of the fifth group, (twisted, muddled, tied), but they supply also an idea of darkness and obscurity, from the moment that all they are nested between the pleats of the conscience or in the pleats of the soul in a place without light and with closed doors. The metaphors of this group are all attributed to the invisible author.

8) simple, smooth (semplice, liscio)

What is simple has only one pleat (from Latin sem, which means one, and semel, which means one time, cfr. gr. hen and plica), or what is simple may also not have any pleats (metaphors do not follow the rules of logic, metaphors have their own reasons). Without pleats means that something is smooth and flat, but also clear and bright, since "s- piega" (from the Italian word spiegare, that is to say to explain, to remove the pleats) means to remove everything that contains pleats, referred to what is folded and complicated. Coincidentally the Italian word spiegazione, explanation (from the Latin ex-planare, ex-plicare), means to remove the pleats and arrange the things on a smooth surface, as for example a well ironed tablecloth stretched over a table. When the thought of an author is presented in this way (as for Lévi-Strauss and Feyerabend), this means that students perceived them with an easiness and a pleasure feeling of the reading experience and of a more direct access to the understanding process.

9) cold (freddo)

With this image and the following terms (warm, far away, near) we enter in a metaphorical field in which the physical feelings overlap over the affectionate ones. In fact, cold is referred to an author, in this case the invisible author, his thought and his writing style, which is not communicative, not accessible, and it gives the impression of chill to whom is trying to approach him. The invisible author (Semprini) is cold, says a student, because he is not present, he does not involve me in.

10) warm (caldo)

The warm thought demonstrates warmness and conveys a human presence, says a student regarding Lévi-Strauss, which is perceived as the author behind the text. The term warmth is associated to the concepts of interest and involvement, and even pleasure. For students it is an intellectual pleasure to see and hear Lévi-Strauss and Feyerabend, which are perceived as more warm authors compared to Semprini.

11) distant, to be in his ivory tower (lontano, in alto)

The text of Semprini is metaphorically imagined as distant and to be in his ivory tower, that is to say distant from the persons who would like to engage in. Because the text is distant, it does not touch the soul's student, it does not impress, it does not engage in. At the same time, this higher position renders the invisible author, Semprini, sophisticated, theoretical, scientific, even if the students recognize a certain positive qualification of the invisible author exactly due to this detachment and to be in his ivory tower position. (Ginzburg, 1976)

12) near (vicino)

Feyerabend (more than Lévi-Strauss) promotes a sense of nearness, even a sense of relationship, developed from an equalitarian disposition feeling, according to some students. The visible author is not imagined to be in the ivory tower (even if Lévi-Strauss is perceived more academic than Feyerabend), but 
rather near, so near that the student can even touch him, arriveing to identify with the visible author.

The possibility to see and to hear the author to be studied promotes a feeling of nearness towards the author at the point that some students feel to establish a direct and personal relationship with the author. This proximity feeling is so strong that the students perceive not only the sound of the voice but also its intonation (Chun, 1988), as well as the breathing of the visible authors (Feyerabend and Lévi-Strauss). The nearness feeling, emphasized by the possibility to hear the voice of the author, promotes in the students a tie, an involvement. But at the same time, in some cases, this relationship is 'too much' and creates also some discomfort. For example, for a student, Feyerabend creates confusion and bother.

\section{Six Metaphorical Opposite Couples}

The most representative metaphorical fields which have been extracted are twelve, arranged in six metaphorical opposite couples, and summarized in Table 3. They are:

The components of these metaphorical couples are not always arranged symmetrically. There is no perfect correspondence between the elements of the first group and those of the second, because metaphors have been spontaneously expressed by students.

Regarding the invisible author's text, it is often defined by the students to be: realistic, precise, scholastic, serious, authoritative. The audio-visible authors, on the other hand, aroused a bigger number of metaphors, such as: fresh air, leaving a trace, freedom, being a testimony, influence, embraces. Taking into account these last terms, particularly significant of the two lists, students define "authoritative" Semprini and they "embrace" Feyerabend and Lévi-Strauss. From one side, according to the students, an auctor is serious, rigorous and authoritative, but also cold and distant. From the other side, we have two human beings which "wrap" and involve in a warm embrace.

This type of conclusions was in a way already implicit in our research, while we were listening the audio-taped interviews and reading the transcripts. Through the recurrent analysis of the data, we supported our anticipated results. What was not possible to speculate before having analyzed the metaphorical repertoires was the types of metaphors used by the students, which has confirmed what we defined as the conventional repertoire composed by metaphorical expressions like: easy/difficult, simple/complex, light/heavy, etc., where the metaphor is defined as "dead" (Ricouer, 1975), hidden, or difficult to identify.

Table 3.

The six metaphorical opposite couples.

\begin{tabular}{cc}
\hline Heavy, dry, sterile & Light, flowing, fluid \\
Hard, hostile & Fragile, sensitive, open \\
Twisted, muddled, tied & $\begin{array}{c}\text { Linear, not twisted, that goes in } \\
\text { one direction } \\
\text { Complex, complicated }\end{array}$ \\
Cold & Easy, smooth \\
Far, to be in the ivory tower & Warm \\
\hline
\end{tabular}

Students referred to this conventional repertoire, but they also produced, in a creative way, unconventional metaphors, which were stimulated by the new instructional system, which implies to use traditional written texts in combination with TV interviews.

We are aware that our instructional system might have also some limitations. In order to replicate these results, we need to create additional experiments with other audio-visible and invisible authors in other disciplines.

\section{Discussion and Some Conclusions}

The metaphors' analysis implies also another explanation which has a profound implication on literacy, literacy development and the development of interest towards new subjects.

If the focus moves from the product of a reading and studying act as a result to understanding the process of it, a different picture of literacy will emerge. Social involvement appears as a fundamental basis of orientation while reading and writing, "making literacy not the narrow ability to deal with texts, but the broad ability to deal with other people as a writer or a reader.” (Brandt, 1990: p. 14)

The oral-literate dichotomy is a relationship of context and text. In speech, the direction of meaning is from context to text; in writing and reading, the direction of meaning is from text to context. Speakers, such as our audio-visible authors, have a context, such as the real world, physical presence, the mutually reliable setting, that the invisible author does not have. The context is the situation, the classroom setting, "the possible world", where time and space define the joint presence of participants. In literate exchange, context is represented only by the text. In oral exchange, context is the taken for granted social world, it is the shared backgrounds of the participants. Context is everything that participants in a conversation know and understand, that contributes to how they make sense of what is said, as in our classroom settings. In both exchanges, literate and oral, inter-subjectivity, such as the mutual recognition of the presence of the other, is the core of interpretation and meaning.

One's own involvement with other people-rather than with texts-is the centre of literate interpretation and development. In fact, according to Brandt (1990), literacy has to be considered as a growing meta-communicative ability —an increasing awareness of and control over the social means by which people sustain discourse, knowledge and reality-a condition where social involvement becomes the key model of literacy and literacy growing. “... making sense of print requires the fundamental realization that written language is about an involvement of writer and reader; its reference and meaning depend on the inter-subjective bonds established in the acts of writing and reading. Developmentally, that makes knowledge about the acts of reading and writing ... the key knowledge for literacy development. Learning to read and write depends critically on immediate social involvements with people who read and write and who can show you how the work goes. More broadly, this perspective suggests that we look toward our ordinary social ties ... as the very means that enables reading and writing. " (Brandt, 1990: p. 32).

In order to do this, we have to move from a product to a process description of literate experience, where context, in- 
volvement, and meta-communication are central. Popular debates about the literacy crisis rely on oral-literate dichotomies by putting print against television and other form of orally base media. But recent scholars - and we share this perspectiveproposed that orality and literacy are best understood as a continuum rather than a dichotomy.

Important is to promote in students a situation of imaginative engagement with texts. Brandt (1990) defines reading as an involvement act, where readers try to reach across texts to other human beings, having to be more consciously aware of what is taking place on the other side of the communication, as is necessary when the discourse is oral. Readers read not to separate from others, but to reach out to them. The motive for reading is to find other minds.

"Learning to read requires learning to maintain-in fact, intensify-reliance on social context even under new and precarious circumstances. Literacy failures are not failures of separation but rather failures of involvement. They arise not from overdependence on context but from the lack of access to a viable context for making sense of print. Instead of viewing the oral as antagonist to the literature, it is necessary to understand better how the oral sustains the literate. If the key knowledge for literacy development is finding out how people do reading and writing, the literacy is indeed dependent on oral transmissions, for this knowledge must be passed mouth-tomouth, person-to-person. Literacy ceases to be an abstract, textengined technology in tension with local practices and loyalties and instead appears as something that flourishes only in local forms, as part of 'how we do things around here'. It is by nature and necessity pluralistic and in flux.” (Brandt, 1990: p. 7)

Because the audio-visible authors were presented in an audio-visual and I-you format, we trust that the oral quality of speech and communication helped students in establishing a new type of reading and studying experience, especially for the less skilled readers. From our results, we can hypothesis that to offer to novice students authors to be studied with the use of multimedia supports, together with their written texts, would be perceived as a cognitive as well as an affective help, augmenting their interest and involvement in studying new authors. We argue that the audio-visible authors' texts (versus the invisible author's text) are the means by which students maintained an inter-subjective bond with these authors. The texts of the audio-visible authors possessed a quality of involvement. The metaphors used by students can be considered important instructional cues for teachers and multimedia instructional designers for how to instructionally offer an author to be studied because her social presence counts.

The digital and multimedia technology is ripe enough to offer students new ways to present learning contents and to collaborate with multimedia archives. Our case study is a testimony that it is possible to find audio-visible interviews with scholars which are usually studied only through texts. Educational research in this area is still new, and we hope to have given a meaningful contribution in this direction.

\section{References}

Black, M. (1993). More about metaphor. In A. Ortony (Ed.), Metaphor and thought (pp. 19-41). Cambridge: Cambridge University Press.

Brandt, D. (1990). Literacy as involvement. The acts of writers, readers, and texts. Carbondale, Illinois: Southern Illinois University Press.
Chun, D. (1988). The Neglected role of intonation in communicative competence and proficiency. The Modern Language Journal, 72, 295-303. doi:10.2307/327507

Collenberg-Plotnikov, B. (2006). Iconic turn. Information Philosophie, 34, 109-122.

Deleuze, G. (1988). Le pli. leibniz et le baroque. Paris: Les éditions de Minuit.

Feyerabend, P. (1981). La scienza in una società libera. Milano: Feltrinelli.

Ginzburg, C. (1976). High and low. the theme of forbidden knowledge in the sixteenth and seventeenth centuries. Past and Present, 73, 28-41. doi:10.1093/past/73.1.28

Glucksberg, S., \& Keysar, B. (1993). How metaphors work. In A. Ortony (Ed.), Metaphor and thought (pp. 401-424). Cambridge: Cambridge University Press.

Haynes, F. (1978). Metaphoric understanding. Journal of Aesthetic Education, 12, 99-115. doi:10.2307/3332050

Haynes, F. (1975). Metaphor as interactive. Educational Theory, 25, 272-277. doi:10.1111/j.1741-5446.1975.tb00691.x

Hegel, G. (1970). Vorlesungen über die Ästhetik I. In E. Moldenhauer (Ed.), Werke (p. 518). Frankfurt: Suhrkamp.

Heidegger, M. (1985). Unterweg zur Sprache. In Klosterman (Ed.), Gesammelte Ausgabe (p. 165), Frankfurt: Suhrkamp.

Inglese, T., Mayer, R. E., \& Rigotti, F. (2007). Pedagogic role of audiovisual TV archives in college classes: Can visible authors reduce the learning gap between native and non-native language speakers? Learning and Instruction, 17, 67-77. doi:10.1016/j.learninstruc.2006.11.006

Lakoff, G., \& Johnson, M. (1980). Metaphors we live by. Chicago \& London: The University of Chicago Press.

Lévi-Strauss, C. (2002). Razza e storia, razza e cultura. Torino: Einaudi.

Lloyd, G. (1966). Polarity and analogy. two types of argumentation in early greek thought. Cambridge: Cambridge University Press.

Martens, E. (2000). Der faden der ariadne, oder warum alle philosophen spinnen. Leipzig: Reclam.

Mayer, R. E. (1993). The instructive metaphor: Metaphoric aids to students' understanding of science. In A. Ortony (Ed.), Metaphor and thought (pp. 561-578). Cambridge: Cambridge University Press.

Ortony, A. (1975). Why metaphors are necessary and not just nice? Educational theory, 25, 45-53. doi:10.1111/j.1741-5446.1975.tb00666.x

Ortony, A. (Ed.). (1993). Metaphor and thought. Cambridge: Cambridge University Press.

Peil, D. (1993). Zum problem des bildfeldbegriffs. In P. Lutzeier (Ed.), Studien zur wortfeldtheorie/studies in lexical field theorie (pp. 185-202). Tübingen.

Petrie, H., \& Oshlag, R. (1993). Metaphor and learning. In A. Ortony (Ed.), Metaphor and thought (pp. 579-609). Cambridge: Cambridge University Press.

Ricoeur, P. (1985). La métaphore vive. Paris: Seuil.

Rigotti, F. (1995). The influence of rhetoric on the ethics. Zeitschrift fuer philosophische Forschung, 49, 241-258.

Rigotti, F. (1996). Cultura animi, cultura dei: Worship as agriculture in early Christianity. Duisburg: Gerhard-Mercator Universitaet Gesamthochschule Duisburg-LAUD.

Rigotti, F. (2002). Il filo del pensiero. leggere, scrivere, pensare. Bologna: Il Mulino.

Rigotti, F. (2003). Le parole della democrazia. Equilibri. rivista per lo sviluppo sostenibile, 2.

Rigotti, F. (2007). Spiegare la piega. Il pensiero delle cose. Milano: Apogeo, 60-68

Sapir, D., \& Crocker, J. C. (1977). The social use of metaphor, University of Pennsylvania Press.

Semprini, A. (2000). Multiculturalismo. La sfida della diversità nelle società contemporanee. Milano:Franco Angeli.

Sticht, T. (1993). Educational uses of metaphor. In A. Ortony (Ed.), Metaphor and thought (pp. 621-632). Cambridge: Cambridge University Press. 